Full mouse
$\begin{aligned} & \text { Draft sequence of } \\ & \text { mouse genome roars } \\ & \text { into public view } \\ & \text { p106 }\end{aligned}$

\title{
Academy protests as agriculture agency abandons visa renewals
}

Virginia Gewin, Washington

The US Department of Agriculture (USDA) is washing its hands of visa renewals for researchers at its facilities who are not US citizens.

The action - which will disrupt the careers of up to 200 postdoctoral researchers and visiting scientists - has alarmed US scientific leaders. They fear that it could presage wider difficulties for foreign researchers in the country in the wake of last September's terrorist attacks.

Bruce Alberts, president of the National Academy of Sciences, brought the USDA's new policy to the attention of John Marburger, President George Bush's science adviser, during an open meeting of the academy's members in Washington at the end of last month.

"It's not a reasonable policy," Alberts said in an interview. "It's going to hurt us more than help us." But he expressed confidence that the policy will be modified or reversed now that Marburger has been made aware of it.

The USDA - citing a lack of ability to monitor the visa-renewal process with the care that now is expected of government agencies - says that it will no longer sponsor any visa applications or extensions.

Among those directly affected are 200 postdocs, visiting scientists and temporary employees at the agency's Agricultural
Research Service laboratories, a network of 100 laboratories that employs about 2,000 scientists. Those affected can continue working until their current visas expire.

The USDA's policy change was triggered by its concerns about another group of immigrants - foreign physicians seeking $\mathrm{J}-1$ visa waivers at the end of their training. In the past three years, the USDA has recommended over 300 of these waivers, which exempt physicians from the usual requirement of returning to their native country after US medical training, provided that they work in rural areas that are short of doctors.

"It is now important for us to know more about the medical doctors and scientists we sponsor," says USDA spokeswoman Alisa Harrison. She adds that the policy remains under review and that the USDA will do what it can to continue to work with the researchers - cooperating, for example, with universities that might sponsor their visa renewals.

The agricultural board of the National Academy has asked Alberts to complain formally to the government about the USDA's new policy. After he complained informally to Marburger on 29 April, Marburger thanked him for raising the issue and pledged to look into it. But a week later, a spokeswoman for Marburger declined to specify what he would do to address the concern, and

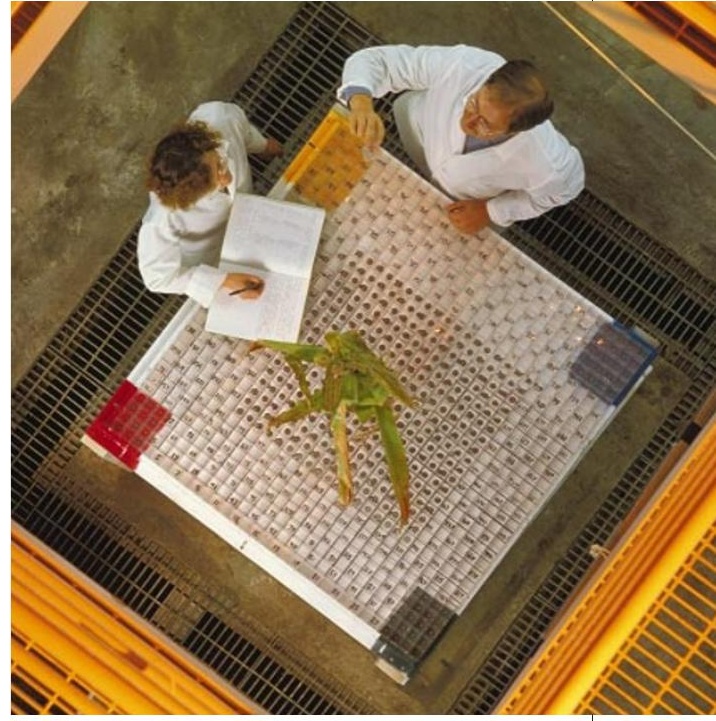

Seeds of doubt: the USDA's new policy could leave foreign researchers unable to renew their visas.

referred questions on the policy to the USDA.

Visas are not the only security issue worrying US science leaders. In his address to the National Academy meeting, Alberts listed several threats that face US science, and placed "the possibility of excessive restrictions on scientific publication, motivated by security concerns", at the top of the list.

\section{Radiologist's confirmation ends NIH power vacuum}

\section{Erika Check, Washington}

The US Senate has confirmed radiologist Elias Zerhouni as director of the National Institutes of Health (NIH), filling a 28-month void at the helm of the world's largest biomedical research agency.

Zerhouni, who was born and medically trained in Algeria, will arrive at the NIH from the Johns Hopkins University School of Medicine in Baltimore, Maryland, where he was vice-dean for research. The Senate confirmed Zerhouni on 3 May, just three days after a smooth confirmation hearing at which he stressed the importance of multidisciplinary science, the translation of basic research into medicine, and better access to new technologies for researchers.

He tactfully told senators that he would support whatever decision the Congress comes up with on the issue of therapeutic cloning (see page 103). He said that he backed President Bush's decision to use federal funds for research only on stem-cell lines that already exist, adding that if researchers needed more of them, he would "be the first to assemble that information" for consideration by policy-makers.

Zerhouni also got firmly behind the creation of the Institute of Biomedical Imaging and Bioengineering at the $\mathrm{NIH}-$ a development that was instigated by Congress but opposed by Harold Varmus, the NIH's previous permanent director.

A healthy backlog of work awaits Zerhouni at his new office in Bethesda, Maryland. Since Varmus left, the NIH has lost several institute directors, and Tommy Thompson, the health secretary, has moved aggressively to centralize some of the agency's functions at his own office in Washington DC. “The most important role of a director right now is to re-establish morale and momentum," Zerhouni told the senators, "and to make the agency even more effective than it has been." 